\title{
Câncer Colorretal: entre o sofrimento e o repensar na vida
}

\author{
Colorectal Cancer: between the suffering and the reappraisal of life \\ Leila Maria Vieira', Barbara Nayara de Oliveira Ribeiro², Márcia Aparecida Nuevo Gatti ${ }^{3}$, Sandra Fiorelli \\ de Almeida Penteado Simeão ${ }^{4}$, Marta Helena Souza de Conti ${ }^{5}$, Alberto de Vitta ${ }^{6}$
}

\footnotetext{
' Doutora em Pediatria pela Universidade Estadual Paulista (UNESP) - Botucatu (SP), Brasil. Docente do curso de Enfermagem da Universidade do Sagrado Coração (USC) Bauru (SP), Brasil.

leila.vieira@usc.br

${ }^{2}$ Graduanda do curso de Enfermagem da Universidade do Sagrado Coração (USC) Bauru (SP), Brasil.

barbara.ribeiro1989@bol.com.br

${ }^{3}$ Doutora em Doenças Tropicais pela Universidade Estadual Paulista (UNESP) Botucatu (SP), Brasil. Docente do curso de Botucatu (SP), Brasil. Docente do curso de
Enfermagem da Universidade do Sagrado Coração (USC) - Bauru (SP), Brasil.

marcia.gatti@usc.br

${ }^{4}$ Doutora em Agronomia pela Universidade Estadual Paulista (UNESP) - Botucatu (SP) Brasil. Docente do Mestrado em Saúde Coletiva da Universidade do Sagrado Coração (USC) - Bauru (SP), Brasil.

ssimeao@usc.br

${ }^{5}$ Doutora em Ginecologia, obstetrícia e mastologia pela Universidade Estadual Paulista (UNESP) - Botucatu (SP), Brasit Dacente do curso de Fisioterapia e do Mestrado em Saúde Coletiva da Universidade do Sagrado Coração (USC) - Bauru (SP), Brasil. madeconti@yahoo.com.br

${ }^{6}$ Doutor em Educação pela Universidade Estadual de Campinas (UNICAMP) -

Campinas (SP), Brasil. Docente do curso de

Fisioterapia e do Mestrado em Saúde Coletiva da Universidade do Sagrado Coração (USC) -

Bauru (SP), Brasil.

albvitta@yahoo.com.br
}

RESUMO Este estudo objetivou compreender as experiências vividas por seis pacientes submetidos à bolsa de colostomia após cirurgia de câncer colorretal. A metodologia foi a "Ground Theory" e o referencial teórico do interacionismo simbólico, que leva à formação de categorias, subcategorias e categoria central. Os dados foram coletados sistemática e simultaneamente, até a saturação teórica. A necessidade da bolsa de colostomia revelou sentimentos que fizeram emergir três fenômenos: sendo surpreendida no pós-operatório; tendo que aceitar a convivência com colostomia e repensando a vida. A análise do processo levou ao desenvolvimento da categoria central CÂNCER COLORRETAL: ENTRE O SOFRIMENTO E O REPENSAR NA VIDA.

PALAVRAS CHAVE: Colostomia; neoplasias colorretais; qualidade de vida; pesquisa qualitativa.

ABSTRACT The aim of this study was to understand the experiences of six patients subjected to using a colostomy bag following surgery for colorectal cancer. The methodology used was the Ground Theory with the theoretical framework of symbolic interaction, which leads to the formation of categories, subcategories and a core category. The data were collected systematically and simultaneously up to the point of theoretical saturation. The need for a colostomy bag revealed feelings that demonstrate three phenomena: feeling surprised postoperatively; having to accept living with a colostomy and rethinking life. The review of the process led to the development of the core category COLORECTAL CANCER: BETWEEN THE SUFFERING AND THE REAPPRAISAL OF LIFE.

KEYWORDS: Colostomy; colorectal neoplasms; quality of life; qualitative research. 


\section{Introdução}

A causa exata do câncer de cólon e reto é desconhecida. Os principais fatores encontrados na literatura, apontados como fatores de risco, são: idade acima de 50 anos; história familiar de câncer de cólon e reto; história pessoal pregressa de câncer de ovário, endométrio ou mama; dieta com alto conteúdo de gordura; ingestão excessiva de carne; baixo consumo de frutas, vegetais e cereais; obesidade; sedentarismo; consumo excessivo de álcool; tabagismo; doenças inflamatórias do cólon, como reto colite ulcerativa crônica; doença de Cronh; e algumas condiçóes hereditárias, como Polipose Adenomatosa Familiar e Câncer Colorretal Hereditário sem Polipose (BRASIL, 2008).

O tratamento do câncer colorretal consiste em procedimento cirúrgico, quimioterapia e radioterapia, sendo as duas últimas terapias associadas à cirurgia. A ressecçấo cirúrgica do local afetado e a realização de uma colostomia permanente constituem-se na mais efetiva terapia para o câncer colorretal, porém, muitos pacientes desconhecem ou náo são informados a respeito do pós-operatório, que culminará na necessidade de utilização da colostomia (BRASIL, 2008).

A ostomia (ou estomia) é conhecida desde o ano 350 a.C. É considerada uma das mais importantes realizaçôes cirúrgicas, pois possibilita a sobrevida da pessoa acometida por câncer colorretal (MARUYAMA; ZAGO, 2005). As razōes mais predominantes para colostomias sáo as neoplasias e os ferimentos por arma de fogo ou arma branca. Nestas últimas condiçóes, a colostomia pode ser temporária, ocorrendo o fechamento em um tempo que varia de acordo com condiçóes relativas ao portador; ou definitiva, perdurando por toda a vida da pessoa (BELATO et al, 2005).

A qualidade de vida $(\mathrm{QV})$ do paciente com câncer colorretal, que é submetido à colocação da bolsa de colostomia, é importante para o tratamento da patologia. Distúrbios da ansiedade ou, até mesmo, depressão são reaçôes esperadas, cabendo ao profissional da área da saúde participar ativamente desse período difícil e complexo (SIMONETTI, 2006).

$\mathrm{O}$ indivíduo ostomizado comumente se sente muito diferente dos demais e até mesmo excluído. Isso decorre do fato de que todo ser humano constrói, ao longo de sua vida, uma imagem de seu próprio corpo, que se ajusta aos costumes, ao ambiente em que vive, enfim, que atende às suas necessidades de sentir-se situado em seu próprio mundo (SILVA; SHIMIZU, 2006).

O sentimento de inutilidade, desgosto, depressão, perda da autoestima, do status social e da libido, além de reforçarem as alteraçōes na dinâmica familiar, causam impacto psicológico, nutrem a fantasia de que perderáo sua capacidade produtiva, levando-os a exteriorizar sentimentos como tristeza, ódio, repulsa e medo (CASCAIS; MARTINI; ALMEIDA, 2007).

A situação pode levar a alteraçóes na vida sexual do paciente, resultando em diminuiçáo ou perda da libido e, por vezes, impotência, todas relacionadas com a alteraçáo da imagem do corpo e a consequente diminuição da autoestima, bem como com a preocupação relacionada à eliminaçấo de odores, aos flatos e às fezes durante a relação sexual (ALVES, 2000).

Considerando o exposto, o presente estudo buscou compreender e explorar sentimentos, expectativas de vida, adaptaçâo social, convívio familiar, relacionamento conjugal e vida espiritual de pacientes que foram submetidos à utilização da bolsa de colostomia após diagnóstico e cirurgia decorrente do câncer colorretal.

\section{Metodologia}

O estudo foi desenvolvido em um Hospital Estadual de Bauru/SP, que oferece assistência em diversas especialidades. A casuística foi composta por seis pacientes com diagnóstico de câncer colorretal, utilizando bolsa de colostomia, que compareceram ao serviço de quimioterapia do hospital nos meses de setembro, outubro e novembro de 2010.

A análise buscou a representação do processo vivenciado e baseou-se no método da Teoria Fundamentada em dados, também denominada Ground Theory, tendo como fio condutor a formação de categorias indicadas por Chenitz e Swanson (1986), que preconizam a nominação dos fenômenos, categorias e subcategorias na forma verbal do gerúndio, por expressar uma açâo em curso ou uma açấo simultânea a outra, e indicam 
os seguintes passos na elaboração do processo: descobrindo categorias, ligando categorias, relato de memorandos e identificação da categoria central.

O propósito do Referencial Teórico Interacionismo Simbólico é compreender as razões da ação humana transformada de maneira que a definição dada pelo indivíduo tenha significado (CHARON, 1989).

A Teoria Fundamentada em Dados é uma metodologia de pesquisa idealizada por Glaser e Strauss (1967), e baseia-se na descoberta e no desenvolvimento de uma proposição gerada por um processo de indução, no qual categorias analíticas emergem dos dados e são elaboradas conforme o trabalho avança.

Os dados foram coletados e analisados sistemática e simultaneamente até o momento em que se chegou à saturação teórica, ou seja, quando nenhum dado novo ou relevante foi encontrado, conforme descreve Strauss e Corbin (1990).

O projeto foi aprovado pelo Comitê de Ética em Pesquisa da Universidade do Sagrado Coração (Protocolo n. 212/10).

\section{Apresentação da Experiência}

A análise compreensiva permitiu a constatação de três fenômenos: 'Sendo surpreendida no pós-operatório'; 'Tendo que aceitar a convivência com a colostomia'; 'Repensando a vida'.

O fenômeno 'Sendo surpreendida no pós-operatório' revela a surpresa vivenciada logo após acordar da cirurgia. A maioria dos pacientes desconhecia a possibilidade de ter que se submeter à colostomia, sendo que muitos deles desconheciam o que é colostomia e quais são as suas finalidades.

Essa situação retrata a falta de conhecimento e informaçóes a respeito dos desdobramentos da cirurgia.

\section{[...] Antes, eu nunca tinha visto a colostomia [...]. \\ [...] A gente fica, assim, preocupada porque é uma coisa que a gente nem nunca ouviu na vida [...]. \\ [...] Mesmo se tivesse falado, eu não tinha co- nhecimento do que era [...].}

O sentimento de impacto ao acordar e se deparar com a colostomia trouxe à tona a incompreensão e a surpresa refletindo a falta de noção sobre como será o futuro.

[...] Eu náo entendi nada quando acordei e me deparei com a colostomia [...].

[...] Nem me foi explicado que eu ia colocar a colostomia [...].

[...] Se eu soubesse que era pra colocar a bolsa, eu não teria feito a cirurgia [...].

[...] O que eu queria era poder conversar com o médico antes da cirurgia, porque ele não me disse o que poderia acontecer [...].

[...] Quem me explicou depois foi a enfermeira, depois você me explicou [...].

A dificuldade de entender e a necessidade de ter de aceitar a conviver com a colostomia retratam um momento de muita angústia e preocupação.

[...] Ainda não caiu a ficha, ainda não (silêncio). É uma coisa que eu vou ter que carregar pro resto da vida [...].

[...] No início, é duro de aceitar, não é fácil de aceitar [...].

[...] Não é fácil passar por tudo isso, não [...].

[...] Eu não aceito [...].

[...] Eu não aceitei no primeiro momento, só que eu não estava evacuando mais [...].

Outro aspecto relevante é a constatação da tristeza do paciente, principalmente pela necessidade da mudança do estilo de vida.

[...] Eu não estou feliz com isso, né? [...]

[...] Nada é mais que nem antes... tudo mudou completamente [...].

[...] Muitas coisas mudaram, dai eu fico triste [...].

[...] Não saio na rua... não saio, não vou mais à missa [...]. Não faço nada de comida mais. [...] Eu fazia caminhada, lavava roupa, passava, fazia comida, fazia tudo ali, fazia meu pão, $e$ agora näo faço mais nada [...]. 
[...] Não dá pra pescar, eu pescava toda vida [...].

[...] Eu fui obrigado a parar de cozinhar [...].

[...] Antes eu gostava de ficar em casa sem camisa, agora não posso mais, de sair na rua. É sair na rua e voltar pra casa correndo [...].

[...] Mas a relação sexual não tem mais [...].

[...] Ah, eu não posso mais pegar o meu neto no colo [...].

[...] Eu gostava de andar de moto [...].

[...] Náo posso jogar bola [...].

Frente ao impacto da situação, o paciente fica confuso diante das mudanças que sofrerá no seu dia a dia, e relata preferir o passado.

[...] Eu preferia trabalhar cem anos, mas não usar isso aqui [...].

[...] Agora ela é pesada, dói, tem mau cheiro[...]. Ah, fora o trabalho todo que dá pra minha filha [...].

[...] A gente se sente reprimido, acha que todo mundo na rua fica te olhando, você percebe que elas olham mesmo [...].

[...] A bolsinha eu acho que a pessoa nunca acostuma, desde a primeira hora, nunca acostuma, ela incomoda [...].

[...] É, você já não fica à vontade em qualquer lugar [...].

[...] Ah, incomoda bastante, não é igual antes, não dá pra namorar minha esposa [...]. [...] Nossa! E fica sujando o dia todo, porque eu tô com diarreia ainda [...].

Vêm à tona as dificuldades da utilização da bolsa de colostomia, pensam sobre o odor que pode exalar e se constrangem, preferem o isolamento, porém, relatam a ajuda de familiares e amigos, os quais colaboram e ajudam com carinho e atenção.

[...] na casa dos outros não tem onde você limpar, ai é complicado [...].
[...] parece que atrapalha, precisa estar sempre esvaziando a bolsinha, sempre, dependendo do que você come [...].

[...] não dá nem pra sair na rua, porque precisa limpar toda hora [...]. Lá em casa tem um banheiro que eu deixo só pra fazer a higiene pessoal [...].

[...] As pessoas não entendem que está fechado, que não vai cheirar. Eu não aceito [...].

[...] você está, assim, no meio de gente, dai parece que cheira, parece que você fica com isso na cabeça [...].

[...] Minha filha me ajuda bastante, na verdade, ela faz tudo [...].

[...] Tem que ficar correndo comigo. E, dos meus filhos, o único que está correndo comigo é o mais velho [...].

[...] o men marido é uma babá que cuida de mim [...]. Eu amo ele [...].

[...] vejo o amor da fraternidade cristá também; apesar de eu estar doente, vejo que sou amada [...].

[...] meu marido que faz tudo, coitado. Se pudesse trazer o céu para mim, ele traria. Ele faz tudo o que eu peço [...].

[...] o amor das pessoas vale a pena a gente passar por tudo isso [...].

[...] meus filhos [...] (choro) [...], eles não fizeram nenhum comentário. Estranharam, só [...].

[...] eu tô muito cansada [...].

Há um período significativo em que o portador de colostomia reflete sobre seu futuro, seus anseios, sua vida profissional e conjugal. Emergem muitas dúvidas e medos com relação ao amanhã.

[...] Penso no que será; penso em tudo, penso nos cuidados, penso na preocupação [...].

[...] Ah, incomoda bastante, náo é igual antes, não dá pra namorar minha esposa, mas... [...] Ela fica em um lugar que incomoda, dá medo, medo de vazar, você já náo sente mais vontade [...]. 
[...] Eu peço que eu volte ao normal [...].

[...] Eu vou namorar minha mulher e, ao tirar minha camisa, eu tenho vergonha [...] mas até a relação marido e mulher prejudicou [...] A sua preocupação é em agradar a sua mulher, mas é uma situação diferente [...].

[...] Perdi tudo, sabe? Perdi minha energia, perdi tudo [...] .

[...] Preocupada com os cuidados que minha filha tem que ter [...].

A mudança é um fato concreto no estilo de vida dos entrevistados, que apontam como é difícil deixar de participar de algumas atividades do cotidiano e que o único caminho é se conformar com o presente a ser vivido.

[...] Mas eu não posso ir de terça a igreja, rezar a missa, rezar o terço [...].

[...] Não saio, não vou mais à missa também, porque eu acho que é falta de respeito.

[...] Minha vida agora é comer e dormir [...]

Fico dentro de casa mesmo [...].

[...] Eu não saio [...].

[...] é do hospital pra casa e da casa pro hospital [...].

[...] Antes, eu gostava [...] de sair na rua, mas não tem como você ficar. É sair na rua e voltar pra casa correndo. [...] Prefiro ficar em casa a sair [...].

[...] Sinceramente, não gosto nem de sair na rua mais [...].

[...] Eu tenho certeza que na empresa que eu levava mantimentos eles não vão deixar eu entrar, porque é uma empresa de produtos alimentícios [...].

[...] Mas, agora, tem que usar. Que toque a vida e que peça a Deus que se conforme [...]

[...] Eu sei que, se eu não cuidar, tem o problema de infecção, de limpeza correta. Eu troco sempre e tal [...].

Apesar de tantas vivências negativas, emergem relatos da importância da religiosidade para encontrar respostas ou conforto para suas dúvidas e anseios. Reconhecem e agradecem o tratamento da unidade de oncologia do Hospital.

[...] mas, agora, tem que usar que toque a vida e que peça a Deus [...].

[...] tem que agradecer a Deus, porque, se você olhar, tem gente bem pior que você [...].

[...] mas só Deus mesmo pra resolver o problema da gente [...].

[...] Vejo o amor da fraternidade cristã, apesar de estar doente, vejo que sou amada[...] [...] eu estou satisfeita com o tratamento do hospital. A gente se apega com as enfermeiras, gosta, deixa agente feliz. Isso contribui para o tratamento, o amor das pessoas vale a pena agente passar por tudo isso. [...] Eu vou retribuir e trazer presente pra todas as enfermeiras, porque a gente quer retribuir o amor demonstrado [...].

A estratégia para descobrir a categoria central foi inter-relacionar os três fenômenos, buscando compará-los e analisá-los para compreender como se dava a interação entre seus componentes. Essa estratégia permitiu identificar as categorias e subcategorias-chave que compreendem o movimento da experiência interacional vivenciada por pacientes com câncer colorretal, portadores de colostomia.

'Sendo surpreendida no pós-operatório' significa o momento no qual o paciente se depara com a colostomia, quando vêm à tona vários sentimentos e dúvidas sobre o que está acontecendo e, principalmente, a respeito de como será o seu futuro. $\mathrm{O}$ paciente passa por um processo de interiorização, assimilando as questóes referentes à cirurgia.

'Tendo que aceitar a convivência com a colostomia', o paciente passa a entender que a melhoria de sua saúde pode ser possível, porém, vivencia situações de muitos sentimentos, tristezas e preocupações, e emerge a necessidade de ficar repensando a vida, o que será possível com a ajuda de familiares, amigos e profissionais da saúde. 
Diante desse movimento, foram constatados os componentes chave da experiência, que possibilitaram denominá-la como 'Câncer colorretal: entre o sofrimento e o repensar na vida'.

\section{Discussão}

O estudo possibilitou compreender a experiência interacional dos pacientes que foram acometidos de um diagnóstico de câncer colorretal - que, após cirurgia, se viram portadores de uma colostomia - e, a partir da experiência vivenciada, desenvolver um modelo teórico representativo.

A opção pelo uso da perspectiva teórico-metodológica, amparada pela Teoria Fundamentada em Dados, permitiu avanços nos conhecimentos sobre o objeto em estudo, quando comparados os achados com aqueles oferecidos pela literatura.

A escolha da categoria central 'Câncer colorretal: entre o sofrimento e o repensar na vida' emergiu pela capacidade de designar e relatar de forma abrangente tal experiência. $\mathrm{O}$ processo vivenciado inclui uma vida particular, social, cultural, econômica, de afeto, amizade, companheirismo, ajuda, entre outros, que cercam cada um dos pacientes, cada qual com suas particularidades. $\mathrm{O}$ estudo buscou fatos comuns entre os discursos dos pacientes, o que tornou possível identificar fenômenos e construir um modelo teórico representativo, que foi validado e é capaz de contextualizar a categoria central de tal estudo.

'Sendo surpreendida no pós-operatório' foi o primeiro fenômeno encontrado. A literatura reforça a importância do conhecimento prévio sobre o pós-cirúrgico. $\mathrm{O}$ cuidado de enfermagem perioperatório engloba o cuidado fornecido antes (pré-operatório), que se inicia no momento em que o paciente recebe a indicação da cirurgia e se estende até sua entrada no centro cirúrgico; durante (intra-operatório), em que o paciente submetese à operação propriamente dita; e depois da cirurgia (pós-operatório), que tem início logo após o procedimento, até a recuperação do paciente (NETTINA, 2003). Constatou-se que o paciente sente a colostomia como mais uma doença, relatando não querer conviver com um estoma. Não havendo a parceria dos profissionais da saúde com o paciente nesse momento, o futuro pode trazer várias decepçóes e desarmonia.

Para Hogan (1991), a qualidade do relacionamento entre os parceiros antes da cirurgia determina o ajuste pós-operatório. Durante essa fase, o paciente ainda tem dificuldade para entender o que é vivenciar tal momento, e relata sentimentos negativos, relacionados com a sua imagem corporal. Munjack e Oziel (1984) e Lopes (1993) entendem que o relacionamento positivo no pré-operatório "é o alicerce da casa", pois, se há existência de conflito, após a cirurgia ele tende a aumentar, gerando angústia e insegurança no pós-operatório.

A comparação entre 17 estudos com pacientes com câncer colorretal, com e sem estoma, indicou que tanto o grupo de pacientes com estoma quanto o grupo de pacientes submetidos a cirurgias preservadoras de esfíncter relataram limitaçóes físicas, psicológicas e sociais. A função física foi afetada por movimentos intestinais irregulares, diarreia, flatulência, problemas urinários e constipação. Psicologicamente, os pacientes apresentaram imagem corporal negativa. A vida social foi afetada - especialmente no que se refere ao trabalho, produtividade, relacionamento interpessoal, atividades de lazer - e houve influência sobre a sexualidade (SPRANGERS et al, 2000).

Pacientes colostomizados, em período pós-operatório, afirmam que se sentem estigmatizados com o estoma, que não têm o seu convívio social diário normal com as pessoas, preferindo o isolamento, e, em decorrência de tal processo, sentem ansiedade e vivenciam períodos de confusão (PETUCO, 1998). Porém, esforçam-se para manter as relaçóes mais próximas, empenhando-se em mostrar-se como alguém comum. Desse modo, conseguem viver, apesar das dificuldades (GOFFMAN, 1982; KELLY, 1992).

Assim, a presença de um estoma pode resultar em uma morbidade psicológica, contribuindo para diminuição/deterioração da qualidade de vida, pois o colostomizado tende a sentir-se estigmatizado, por julgar-se diferente, ou seja, por não apresentar as características e os atributos considerados normais pela sociedade (SILVA; SHIMIZU, 2007). 
Em estudo realizado por Sonobe, Barichello e Zago (2002), observou-se, também, que a presença da colostomia faz com que o paciente tenha que se deparar com a sua nova condição. Modificaçóes fisiológicas gastrointestinais, cuidados com a bolsa de colostomia, surgimento de sentimentos conflituosos, preocupaçóes e dificuldades para lidar com essa nova situação levam os ostomizados a visualizar as suas limitaçóes e enfrentar as mudanças ocorridas no seu cotidiano.

A perda do controle da eliminação de fezes e gases pode acarretar o isolamento psicológico e social, baseado em sentimentos negativos que permeiam as relações interpessoais (MICHELONE et al, 2004).

A criação de um ânus artificial e incontinente na parede abdominal leva o ostomizado a vivenciar uma alteração da imagem corporal, da autoimagem e da identidade ligada à lesão do próprio corpo, assim como a perda da habilidade de controlar a eliminação das fezes, além dos conflitos pela dissociação entre a imagem idealizada e a real. Todos esses sentimentos sofrem influências e também passam a influir na personalidade do indivíduo (TRENTINI; SILVA, 1992; SOUZA; SANTOS, 1996). Sentimentos de inferioridade, redução da autoestima, insegurança e crença da rejeição pelos outros indivíduos foram encontrados pelos indivíduos do estudo.

Com relação às transformaçóes do corpo, as pessoas ostomizadas apresentam prejuízo na estética corporal e, consequentemente, na autoestima. Devido ao estoma e ao uso de bolsa coletora, elas têm a necessidade de modificar o modo de vestir, sobretudo usando roupas largas, que têm como propósito ocultar o dispositivo coletor (SILVA; SHIMIZU, 2006).

Os hábitos alimentares precisam ser modificados para evitar a flatulência excessiva e outras complicaçóes, como a diarreia, sendo necessário ter controle alimentar rigoroso para evitar tais situaçóes (SILVA; SHIMIZU, 2006).

As pessoas têm experiências particulares e únicas de sofrimento, e percebem mudanças quantitativas e qualitativas na medida em que a causa do sofrimento vai-se modificando com o tempo, não somente no âmbito orgânico, mas também em outras dimensóes de sua vida, tanto social quanto emocional (MERCADO-MARTÍNEZ et al, 1999).

A vivência de um câncer e de uma colostomia causa um impacto duplo na vida da pessoa. O primeiro é atribuído à incerteza da cura, à possibilidade da morte eminente; num segundo momento, o impacto provoca a deterioraçáo da imagem, a vergonha e o medo da rejeição (CASCAIS; MARTINI; ALMEIDA, 2007)

A visão que o ostomizado tem sobre o uso da bolsa de colostomia constitui desafio para sua adaptação à nova condiçấo. Ele necessita rever o seu momento de perdas para encontrar forças para aceitar e trabalhar novas perspectivas de vida (SONOBE; BARICHELLO; ZAGO, 2002).

O impacto de uma colostomia na vida de qualquer pessoa traz consequências que se refletem em diferentes aspectos, entre eles, biológico, psi-cológico, social e espiritual, sendo a alteração da autoestima uma das mais importantes. Ressalta-se que as reaçóes a respeito da colostomia são fundamentais na recuperação física do paciente, na sua autoestima, autoconfiança e no retorno às atividades sociais (COSTA; MARUYAMA, 2004).

A adaptação depende do apoio, do estímulo e da compreensão encontrados nas pessoas ou em profissionais de saúde que fazem parte do suporte social, e isso poderá determinar a visão sobre a sua condição de ostomizado, influenciando-o na retomada de sua vida (SONOBE; BARICHELLO; ZAGO, 2002).

$\mathrm{O}$ apoio e o estímulo oferecidos pelas pessoas significativas podem ajudar o paciente a superar os sentimentos de perda, negação, revolta e falta de es $\neg$ perança. Eles se apegam a esse apoio, como se fosse um porto seguro para modificar e superar as suas limitaçóes (SONOBE; BARICHELLO; ZAGO, 2002).

É necessário o desenvolvimento do trabalho em equipe, pela complexidade do processo de reabilitação dessas pessoas, sendo fundamental a atuação multiprofissional de saúde, constituída por médicos, enfermeiros, assistente social, nutricionista, psicólogos, entre outros, a fim de construir um planejamento de assistência discutido e compartilhado por todos (SILVA; SHIMIZU, 2006). 
A estomaterapia apresenta um significado que transcende o tradicional, trilhando um caminho objetivo e definido, a fim de produzir uma nova representação do ser enfermeiro na sociedade, contribuindo para o seu reconhecimento como um profissional singular e essencial na prática de saúde (PAULA; SANTOS, 2003).

Diante de tal trabalho - entrevistas com os pacientes - constatou-se a necessidade da interação entre estes e os profissionais da saúde, desde a descoberta da doença, no processo pós-operatório, durante sua internação e, até mesmo, após a alta hospitalar, permitindo, também, verificar a necessidade da ajuda por parte dos familiares, amigos, da religião e da própria instituição.

\section{Considerações Finais}

Os achados deste estudo, mediante a pesquisa qualitativa, possibilitaram a compreensão de como é a experiência de conviver com a colostomia, sob a percepção de indivíduos que foram submetidos a tal procedimento.

A análise dos relatos revelou a surpresa ao se depararem com a colostomia no pós-operatório, até a fase da conformidade, e a necessidade de enfrentamento na convivência social. Constatou-se que esse processo é permeado pela tristeza, por prejuízos à autoimagem, depressão, ansiedade, inquietação, dor, nojo, recusa da família, abdicação dos hobbies, afastamento da vida profissional, apego à religiáo e aos amigos, vergonha, medo de sair à rua e de conviver socialmente.

Para tais pacientes, enfrentar a convivência com a colostomia revelou uma grande luta interna entre os aspectos físico, espiritual e emocional, e a expressão do desejo de cura.

É importante ressaltar a necessidade de humanização dos profissionais da área da saúde, permitindo diálogo claro e objetivo com os pacientes, náo admitindo que os mesmos se surpreendam ao voltar do centro cirúrgico, mas, sim, que entendam o procedimento antes de realizá-lo.

A equipe de enfermagem necessita de capacitação e treinamento sobre a colostomia para orientar sobre os cuidados que o paciente deverá adotar, com humanização, permitindo que o mesmo esclareça suas dúvidas e expresse seus sentimentos.

A família e os amigos são essenciais na recuperação e na manutenção da vida dos pacientes com colostomia, sendo indispensável haver compreensão em seu dia a dia, para amenizar seu sofrimento e para que possam encontrar novos caminhos.

\section{Referências}

ALVES, L.C.A. Correlação entre adaptação psicossocial à colostomia permanente e resposta psicológica ao câncer. Psiquiatria na prática médica, São Paulo, v. 33, n. 4, out/dez. 2000. Disponível em: <http://www.unifesp.br/dpsiq/polbr/ppm/original4_01.htm>. Acesso em: 25 nov. 2006.

BELATO, R. et al. A convergência cuidado-educação-politicidade: um desafio a ser enfrentado pelos profissionais na garantia aos direitos à saúde das pessoas portadoras de estomias. Texto e Contexto Enfermagem, Florianópolis, v.15, n.2, p.334-342, 2005.

BRASIL. Ministério da Saúde. Secretaria de Atenção à Saúde. Instituto Nacional do Câncer. Coordenação de Prevenção e
Vigilância. Estimativa 2008: incidência de câncer no Brasil. Rio de Janeiro: INCA, 2008. Disponível em: <www.inca.gov.br>. Acesso em: 15 nov. 2008.

CASCAIS, A.F.M.V.; MARTINI, J.G.; ALMEIDA, P.J.S. O impacto da ostomia no processo de viver humano. Texto e Contexto: Enfermagem, Florianópolis, v.16, n. 1, p.163-167, 2007.

CHARON, J.M. Symbolic Interactionism: an introduction, an interpretation. 3 ed. New York: Pretince Hall, 1989.

CHENITZ, W.C.; SWANSON, J.M. From practice to grounded theory. New York: Addison Wesley, 1986. 259 p. 
COSTA, I.G.; MARUYAMA, S.A.T. Implementação e avaliação de um plano de ensino para a auto-irrigação de colostomia: estudo de caso. Revista Latino-Americana de Enfermagem, Ribeirão Preto, v. 12, n. 3, p.557-563, 2004.

GLASER, B.; STRAUSS, A. The discovery of grounded theory. New York: Aldene de Gruyter, 1967. 271p.

GOFFMAN, E. Estima: notas sobre a manipulação da identidade deteriorada. 4 ed. Rio de Janeiro: Zahar, 1982.

HOGAN, R. Human sexuality: a nursing perspective. 2. ed. Connecticut: Appleton-Century-Crofts, 1991.

KELLY, M.P. SELF, identity and radical sugery. Sociology of Health Illness, Hoboken, v. 14, n. 3, p. 309-320, 1992.

LOPES, G.P. Sexualidade Humana. 2. ed. Rio de Janeiro: Medsi, 1993.

MARUYAMA, S.A.T.; ZAGO, M.M.F. O processo de adoecer do portador de colostomia por câncer. Revista Latino-Americana de Enfermagem, Ribeirão Preto, v. 13, n. 2, p. 216-222, mar-abr. 2005.

MERCADO-MARTÍNEZ, F. J. et al. La perspectiva de los sujetos enfermos: reflexiones sobre pasado, presente y futuro de la experiência del padecimiento crónico. Cadernos de Saúde Pública, São Paulo, v.1, n.15, p 179-86, 1999.

MICHELONE, A.P.C. et al. Qualidade de vida de adultos com câncer colorretal com sem ostomia. Revista Latino-americano em Enfermagem, Ribeirão Preto, v. 12, n. 6, p. 875-883, nov.-dez., 2004.

MUNJACK, D.J.; OZIEL, L.J. Sexologia, diagnóstico e tratamento. São Paulo: Ateneu, 1984.

NETTINA, S.M. Prática de Enfermagem. Rio de Janeiro: Guanabara Koogan, 2003.

PAULA, M.A.B; SANTOS, V.L.C.G. O significado de ser especialista para o enfermeiro estomaterapeuta. Revista Latino-americano em Enfermagem, Ribeirão Preto, v. 11, n. 4, p.474-482, 2003.
PETUCO, V. M. A bolsa ou a morte: estratégias de enfrentamento utilizadas pelo ostomizado de Passo Fundo/RS. 220f. 1998. Dissertação (Mestrado) - Faculdade de Saúde Pública. Universidade de São Paulo, São Paulo, 1998.

SANTOS, V.L.C.G. A bolsa na mediação estar ostomizado-estar profissional: análise de uma estratégia pedagógica. 174f. 1996. Tese (doutorado) - Universidade de São Paulo, São Paulo, 1996.

SILVA, A.L.S.; SHIMIZU, H.E. O significado da mudança no modo de vida da pessoa com estomia intestinal definitiva. Revista LatinoAmericana de Enfermagem, Ribeirão Preto, v. 14, n. 4, p. 483-549, 2006.

SIMONETTI, A. Manual de Psicologia Hospitalar: mapa da doença. São Paulo: Casa do Psicólogo, 2006.

SONOBE, H.M.; BARICHELLO, E.; ZAGO, M.M.F. A visão do colostomizado sobre o uso da bolsa de colostomia. Revista Brasileira de Coloproctologia, Rio de Janeiro, v. 48, n.3, p.341-348, 2002.

SPRANGERS, M. A. G. et al. Which chronic conditions areassociated with better or poorer quality of life? Journal of Clinical Epidemiology, Otawa, v.53, p. 895-907, 2000.

STRAUSS, A; CORBIN, J. Basics of Qualitative Research. Thousand Lage Daks: Lage publications, 1990. 267 p.

TRENTINI, M.; SILVA, D.G.V. Condições crônicas de saúde e o processo de ser saudável. Texto e Contexto: Enfermagem, Florianópolis, v. I, n. 2, p. 76-88, 1992.

Recebido para publicação em Novembro/2011

Versão final em Maio/2013

Conflito de interesse: não houve

suporte financeiro: inexistente 